\title{
Management of the renal adverse effects of lithium
}

\author{
Sumeet Gupta, Mukesh Kripalani, Udayan Khastgir \& Joe Reilly
}

\begin{abstract}
SUMMARY
Lithium is one of the most effective psychotropic drugs we have, but it is underused because of its low therapeutic index, the need for regular blood tests and perceptions about its adverse effects, including renal problems. The last include urinary concentration deficits and diabetes insipidus, chronic kidney disease (including renal failure), nephrotic syndrome, hypercalcaemia, hyperparathyroidism and distal tubular acidosis. This article reviews these adverse effects with special emphasis on their management.
\end{abstract}

\section{DECLARATION OF INTEREST}

S.G. has received financial support to attend conferences from AstraZeneca and Lundbeck. M.K. has received financial support to attend a conference from Bristol-Myers Squibb and Reckitts.

Lithium has been used in psychiatry for the past six decades. It is a first-line treatment for bipolar disorder and an established augmenting agent for depression. However, in spite of growing evidence of its efficacy and anti-suicidal effect, its use has gradually declined and many less-established drugs are preferred. The declining trend is usually attributed to problems associated with lithium's low therapeutic index, adverse effects and the need for blood monitoring. One of the most frequently cited adverse effects is the drug's impact on renal function (Gitlin 1999; Young 2007).

The available research evidence of adverse effects of lithium, including renal effects, is meagre in comparison with the evidence of its effectiveness. Furthermore, the picture is confused by the less rigorous and smaller studies of the drug's adverse renal effects, leading to controversies about their extent and even their existence. Mogens Schou, one of the pioneers who established the role of lithium in psychiatry, concluded in a literature review that 'lithium treatment is not nephrotoxic' (Schou 2003). However, over the past decade, studies have shown that lithium use does cause impairment of urinary concentration, glomerular dysfunction and other renal adverse effects (Table 1). In a small proportion of patients, the glomerular filtration rate (GFR) gradually declines; some subsequently develop chronic renal insufficiency, and a very small minority develop renal failure (Gitlin 1999; McKnight 2012). The purpose of this article is to provide an overview of the renal adverse effects of lithium and their management.

\section{Lithium pharmacokinetics}

Lithium is completely absorbed in the upper gastrointestinal system. It is almost entirely
Sumeet Gupta is a consultant psychiatrist in a community mental health team and specialist affective disorder service in Tees, Esk and Wear Valleys NHS Foundation Trust (TEWV). His research interests include management of affective disorder, evidence-based medicine and clinical trials of psychotropic drugs. Mukesh Kripalani is a consultant psychiatrist in the TEWV crisis team, access team and substance misuse team. He has an active interest in lithium prescribing, along with an overall interest in evidence-based practice. Udayan Khastgir is a consultant psychiatrist on an acute in-patient ward. His research interests include management of treatment-resistant psychosis and evidence-based medicine. Joe Reilly is Professor of Mental Health at Durham University and Clinical Director for Research and Development at TEWV. His research interests are psychotropic drug safety, and the diagnosis and treatment of personality disorder. Correspondence Dr Sumeet Gupta, Consultant Psychiatrist, West Park Hospital, Edward Pease Way, Darlington DL2 2TS, UK. Email: Sumeet.Gupta@nhs.net

TABLE 1 An overview of renal adverse effects of lithium

\begin{tabular}{|c|c|c|c|c|}
\hline Adverse effect & Prevalence $^{a}$ & Onset & $\begin{array}{l}\text { Response to lithium } \\
\text { withdrawal }\end{array}$ & Clinical significance $^{b}$ \\
\hline $\begin{array}{l}\text { Impaired urinary concentration and } \\
\text { diabetes insipidus }\end{array}$ & Very common to common & $\begin{array}{l}\text { Usually within a few } \\
\text { months }\end{array}$ & $\begin{array}{l}\text { Reversible initially, but may } \\
\text { become irreversible later }\end{array}$ & Low to moderate \\
\hline Stage 1-3 chronic kidney disease & Common & Usually after long-term use & $\begin{array}{l}\text { ?Reversible up to a stage, } \\
\text { after that irreversible }\end{array}$ & Moderate \\
\hline Stage 5 chronic kidney disease & Uncommon to rare & Usually after $10-20$ years & Irreversible & High \\
\hline $\begin{array}{l}\text { Hypercalcaemia/ } \\
\text { hyperparathyroidism }\end{array}$ & Common & Usually after long-term use & Reversible in some patients & Low to moderate \\
\hline Nephrotic syndrome & Very rare & Usually within a year & Reversible & High \\
\hline Acute renal failure & Rare & $\begin{array}{l}\text { As a consequence of } \\
\text { lithium toxicity }\end{array}$ & Usually reversible & High \\
\hline Distal tubular acidosis & Rare & Usually after long-term use & Not known & Low \\
\hline
\end{tabular}

a. Frequency: very common ( $\geq 1 / 10)$; common ( $>1 / 100$ to $<1 / 10)$; uncommon $(>1 / 1000$ to $\leq 1 / 100)$; rare $(>1 / 10000$ to $\leq 1 / 1000)$; very rare $(\leq 1 / 10000)$.

b. Clinical significance is based on clinical consequences to the patient and the need for the clinician to intervene. 
excreted by the kidneys and is freely filtered by the glomeruli. Most of the filtered lithium is absorbed at the proximal tubule and loop of Henle. A small proportion of the filtered lithium is absorbed at the distal collecting tubule through the epithelial sodium channel $(\mathrm{ENaC})$. Serum levels of lithium are increased when the GFR is decreased by chronic kidney disease (Grunfeld 2009). Levels may also increase as renal function deteriorates as a result of the ageing process. Until the fourth decade of life glomerular function remains well maintained, but thereafter it declines by about $8 \mathrm{ml} / \mathrm{min} / 1.73 \mathrm{~m}^{2}$ body surface area per decade (Weinstein 2010).

\section{Impaired urinary concentration and diabetes insipidus}

Impaired urinary concentration is the most common renal adverse effect of lithium, affecting up to $40 \%$ of patients on the drug (Stone 1999). It presents with the symptoms of polyuria, nocturia and polydipsia. In many patients these effects are mild, but in a small proportion they can be distressing and severe, and some develop diabetes insipidus - the passage of large volumes (>3 l/24h) of hypotonic urine (Kanfer 2000).

These symptoms become obvious fairly soon after initiation of lithium therapy and they can be detected as early as 8 weeks (Boton 1987). They are potentially reversible during the first 6 years of exposure (Grandjean 2009). Some small studies suggest that extended-release formulations of lithium or once-daily (single) dosing might be associated with less urinary volume and decreased maximal urine concentration capacity (Miller 1985; Kusalic 1996).

Various mechanisms have been proposed to explain urinary concentration deficits. These include interference with the stimulatory effect of anti-diuretic hormone $(\mathrm{ADH})$ on collecting ducts and reduction of aquaporin-2 water channels (these are responsible for absorption of water in the collecting ducts). Last, lithium also increases the production of renal prostaglandin E2, which can also lead to diuresis (Grunfeld 2009).

\section{Management of impaired urinary concentration and diabetes insipidus}

Patients on lithium should be routinely asked about thirst, urine output and nocturia. However, polydipsia is less specific than polyuria and nocturia, as it can also be a side-effect of concomitant medications such as tricyclic antidepressant, anticholinergic and antipsychotic drugs (Bendz 1994). Contrary to most guidelines, which do not advocate investigations, Raja (2011) has suggested an annual assessment of urine production as a useful way of identifying urinary concentration deficits and monitoring of polyuria in patients taking lithium. Our opinion is that screening patients for symptoms before embarking on further investigations would be a more costeffective and useful way to identify those at high risk (Fig. 1).

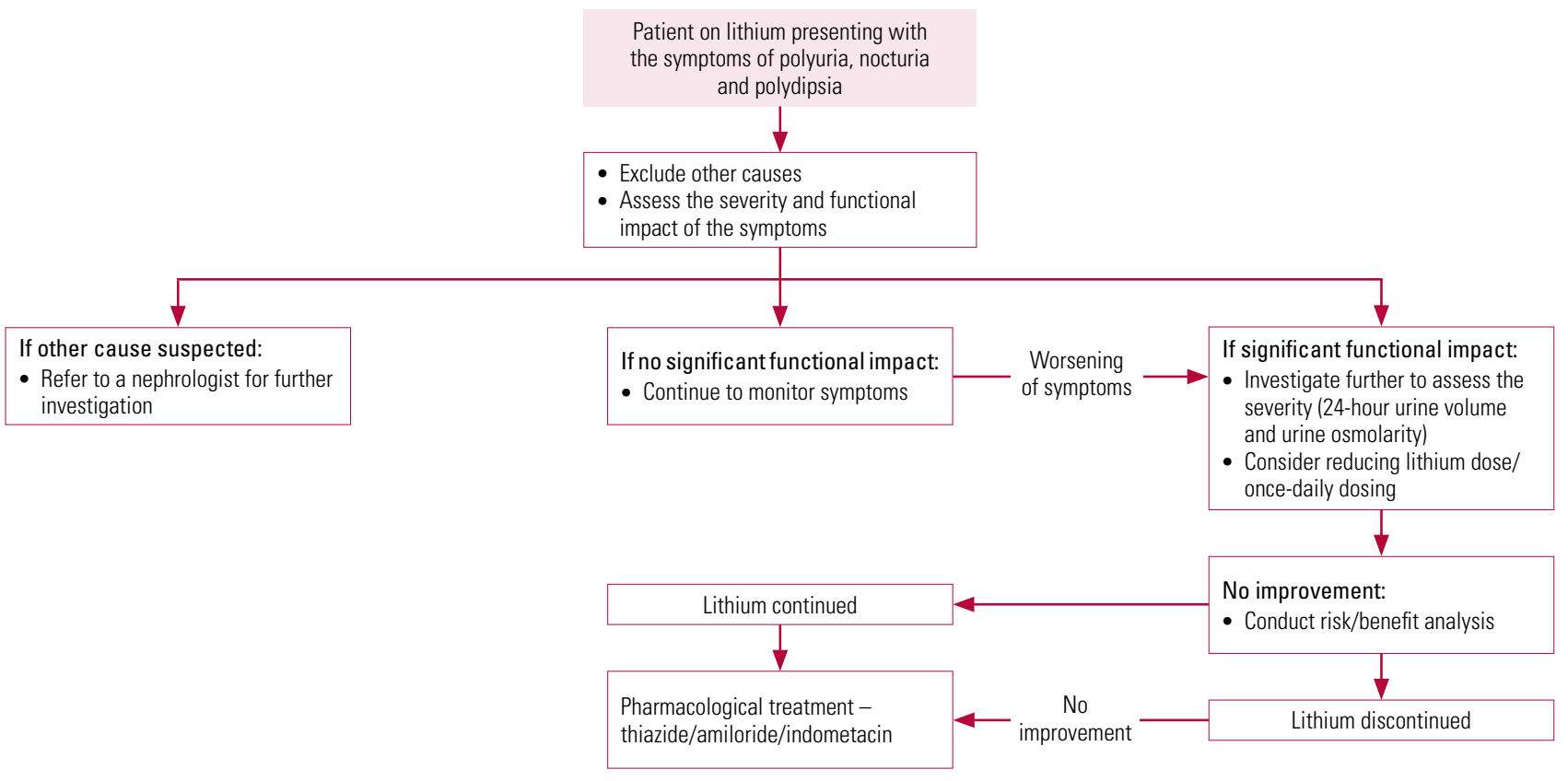




\section{Screening}

If a patient presents with symptoms of urinary concentration deficits, then the first step is to assess the severity and frequency of the symptoms and their functional impact.

The typical symptoms starting soon after the commencement of lithium are usually diagnostic of urinary concentration deficits. Measurement of $24 \mathrm{~h}$ urinary volume, although a cumbersome process, will provide information about the severity of the problem. Other methods of investigation are via urinary specific gravity and osmolarity. Urinary osmolarity should be preferred over specific gravity, as it is not affected by large molecules such as protein, glucose and bilirubin (Jefferson 2010). Finally, a water deprivation test and ancillary investigations can help in differentiating nephrogenic from central causes of diabetes insipidus, but these should be carried out in liaison with a nephrology service.

\section{Intervention}

If the symptoms are persistent and problematic, all options, including replacing lithium with an alternative, should be discussed with the patient. There is some evidence that these side-effects are dose-related, so maintaining serum lithium at the lower end of the therapeutic range may reduce their severity (DePaulo 1986; Grandjean 2009). It is also worth considering a once-daily dose or sustained-release formulation, although evidence supporting the efficacy of these is very limited (Miller 1985; Gitlin 1999). If these strategies fail, then stopping lithium should be considered, after careful risk-benefit analysis (we will return to this later).

\section{Diuretics}

If lithium is continued because of its effectiveness despite these side-effects, or the side-effects persist even after the cessation of lithium, then the following interventions can be considered.

The most commonly recommended treatment is with thiazide diuretics. The use of a diuretic appears counterintuitive, but it has been postulated that thiazide decreases extracellular fluid and encourages proximal tubular absorption, which is not regulated by anti-diuretic hormone. Care should be taken with regard to its interaction with lithium, and the dose of lithium may need to be reduced.

Recent evidence supports the use of amiloride over thiazide, as it decreases the uptake of lithium by epithelial cells and hence is unlikely to increase serum lithium levels. This potentially makes it a drug of choice, as it might also reduce the risk of nephropathy (Grunfeld 2009).

Last, there are a few case reports of the use of indometacin, which inhibits prostaglandins. However, vigilance is needed here because of the possibility of lithium toxicity in the short term and the direct nephrotoxic effect of indometacin in the long term. Amiloride is less effective in severe cases, and in these cases indometacin should be preferred (Raja 2011).

\section{Chronic kidney disease}

The various degrees of glomerular dysfunction are described by terms such as 'renal impairment', 'renal insufficiency' and 'chronic renal failure'. In its clinical guideline, the National Institute for Health and Care Excellence (NICE) replaces such terms with a single category of chronic kidney disease (CKD), which it divides into five stages of severity (Table 2). Stage 5 (commonly called CKD 5) is used synonymously with other terms such as 'established renal failure' and 'end-stage renal disease'.

The effect of lithium on glomerular function has been a contentious issue for some time. However, relatively recent epidemiological studies from nephrology clinics, general practice and laboratory databases have demonstrated that lithium is associated with deterioration of glomerular function and can occasionally lead to end-stage renal disease/CKD 5 (Bassilios 2008; Reilly 2009; Bendz 2010).

Studies have shown that a significant proportion of patients (20\%) develop renal insufficiency, but fortunately CKD 5 is not a common outcome; it affects about $1 \%$ of patients who have taken lithium for more than 15 years (Lepkifker 2004; Bendz 2010; Raja 2011). A retrospective cohort

\section{TABLE 2 Stages of chronic kidney disease according to NICE guidelines}

\begin{tabular}{|lcl|}
\hline $\begin{array}{l}\text { CKD } \\
\text { stage }\end{array}$ & $\begin{array}{c}\text { GFR (ml/min/1.73 } \mathbf{~}^{\mathbf{2}} \\
\text { body surface) }\end{array}$ & Description \\
\hline 1 & $\geq 90$ & $\begin{array}{l}\text { Normal or increased GFR, with other evidence of } \\
\text { kidney damage }\end{array}$ \\
\hline 2 & $60-89$ & $\begin{array}{l}\text { Slight decrease in GFR, with other evidence of } \\
\text { kidney damage }\end{array}$ \\
\hline $3 a$ & $45-59$ & $\begin{array}{l}\text { Moderate decrease in GFR, with or without other } \\
\text { evidence of kidney damage }\end{array}$ \\
\hline $3 b$ & $30-44$ & $\begin{array}{l}\text { Severe decrease in GFR, with or without other } \\
\text { evidence of kidney damage }\end{array}$ \\
\hline 5 & $15-29$ & Established renal failure \\
\hline
\end{tabular}

CKD, chronic kidney disease; GFR, glomerular filtration rate; NICE, National Institute for Health and Care Excellence. a. Use the suffix (p) to denote the presence of proteinuria when staging CKD.

Source: National Collaborating Centre for Chronic Conditions (2008). 
study of the General Practice Research Database in the UK reported that patients with bipolar disorder on lithium had a twofold increased risk of developing renal failure and a two-and-a-half-fold increased risk of developing chronic kidney disease of any stage in comparison with lithium-naive patients (Reilly 2009). A Swedish retrospective cohort study (Bendz 2010) found that 18 out of $3369(0.5 \%)$ patients on lithium suffered from endstage renal disease requiring renal replacement therapy (dialysis or renal transplant). However, further methodologically rigorous studies need to be carried out to inform us about the precise incidence and prevalence of different stages of chronic kidney disease and their determinants.

Lithium-induced renal insufficiency is asymptomatic. Typical biopsy findings are chronic interstitial nephritis, focal sclerosis and tubular atrophy presenting as small cystic lesions (Gitlin 1999; Grunfeld 2009).

Probable risk factors for glomerular dysfunction are listed in Box 1. There are suggestions that cumulative dosages of lithium and higher serum lithium levels are implicated, but further evidence is needed to confirm this (Gitlin 1999; Raja 2011). The pathophysiology is still poorly understood.

\section{Management of chronic kidney disease How should glomerular function of patients on lithium be monitored?}

Early identification is the key to management of chronic kidney disease, since susceptibility to the nephrotoxic effects of lithium differs from one patient to another, for unidentified reasons. Unlike tubular adverse effects, the glomerular effect is usually a long-term one. Sometimes patients with chronic kidney disease present with an episode of lithium toxicity (owing to the impaired renal function, plasma lithium levels increase on the same dosages). Hence, all patients with lithium toxicity should be investigated for renal impairment.

BOX 1 Probable risk factors for lithiuminduced renal changes

- Lithium-related risk factors: cumulative dosage, duration of treatment, multiple dosing, higher serum levels, episodes of lithium toxicity

- Concomitant use of other nephrotoxic medications non-steroidal anti-inflammatory drugs, angiotensin converting enzyme inhibitors, etc.

- Pre-existing or associated somatic illness: diabetes, hypertension, obesity, cardiovascular disease, hyperparathyroidism
Most guidelines recommend blood monitoring for renal function at intervals ranging from 3 to 12 months. However, guidelines are usually vague regarding types of test and their frequency: for example, the NICE clinical guideline CG38 (National Collaborating Centre for Mental Health 2006) suggests 6-monthly monitoring of renal function (via serum urea and creatinine).

Glomerular function can be monitored using the following investigations.

\section{Serum creatinine}

Serum creatinine levels are a crude measure of renal insufficiency. They may remain within the normal range despite significant reduction of glomerular function. They are also affected by muscle mass and diet: creatinine levels are low in patients of low muscle mass, and a high-meat diet or high-protein supplementary drinks can increase levels (Jefferson 2010).

\section{Glomerular filtration rate (GFR)}

Measuring the GFR via clearance of creatinine or of chromium-51-ethylenediaminetetraacetic acid (EDTA) is not advised as a routine investigation, because of the cumbersome nature of the process and its associated cost (Jefferson 2010).

\section{Estimated glomerular filtration rate (eGFR)}

The eGFR is a simpler and preferred test which takes into account some of the factors that complicate serum creatinine interpretations. There are many formulae available for measuring eGFR: the NICE guideline CG73 recommends the 'modification of diet in renal disease' (MDRD) equation, which calculates eGFR on the basis of serum creatinine, gender, age and race (National Collaborating Centre for Chronic Conditions 2008a).

Although the MDRD formula offers a convenient way of measuring eGFR, its clinical significance should be interpreted with a few caveats. First, it significantly 'underestimates' true GFR above $60 \mathrm{ml} / \mathrm{min} / 1.73 \mathrm{~m}^{2}$, especially in obese individuals (Stevens 2007). Hence, concerns have been raised about using eGFR as a screening test for chronic kidney disease, as it leads to a very high number of false positives. Second, only a minority of patients who develop chronic kidney disease will develop end-stage renal disease, hence eGFR has very poor positive predictive value (Ishani 2006). Finally, eGFR is an estimate and has a wide confidence interval. The $90 \%$ confidence interval lies within $30 \%$ of the estimated value. Thus, a result of $60 \mathrm{ml} /$ $\mathrm{min} / 1.73 \mathrm{~m}^{2}$ may represent a true value between 42 and $78 \mathrm{ml} / \mathrm{min} / 1.73 \mathrm{~m}^{2}$ (Stevens 2006). 
In light of these limitations, one abnormal eGFR value should not be given undue importance. However, if consecutive eGFR calculations show persistently low values or gradual deterioration, then the matter should be further investigated. Steep falls in eGFR or persistently low eGFR values are more ominous signs in a young patient than is a gradual decline in an elderly patient.

Guideline CG73 suggests that in patients with a new finding of reduced eGFR, the eGFR test should be repeated within the 2 weeks to exclude acute deterioration in renal function (National Collaborating Centre for Chronic Conditions 2008a). Furthermore, to identify progressive chronic kidney disease, it recommends a minimum of three GFR estimations over a period of not less than 90 days. More attention should be given if extrapolation of the current rate of decline indicates that renal replacement therapy would be needed within the patient's lifetime.

\section{Proteinuria}

Small amounts of protein are normally excreted in urine. Increased and persistent proteinuria is a sign of kidney (usually glomerular) damage. Screening for proteinuria has become important, as it is easy to undertake and predicts cardiovascular morbidity and mortality. Moreover, it may be a better predictor of decline in renal function than eGFR.

As an alternative to direct measurement there are various methods for quantifying proteinuria, such as the albumin:creatinine ratio (ACR) and the protein:creatinine ratio (PCR). Proteinuria in glomerular diseases is primarily caused by increased albumin excretion, and in adults, albuminuria is a more sensitive marker than total protein for chronic kidney disease. Hence, urinary albumin measurement is preferred. Furthermore, on grounds of cost and ease, the ACR is preferable to $24 \mathrm{~h}$ urine collection.

There is very limited research evidence about the extent and significance of proteinuria in lithium-induced nephropathy, although there is some suggestion that patients with proteinuria are more likely to progress to end-stage renal disease than those without (Presne 2003). Kripalani et al (2009) have published an algorithm based on NICE guideline CG73 (National Collaborating Centre for Chronic Conditions 2008a) that uses proteinuria monitoring to manage lithium-related chronic kidney disease. However, further studies are required to establish the utility of proteinuria measurement in the management of lithiuminduced nephropathy.
Magnetic resonance imaging (MRI)

Lithium-induced nephropathy typically presents with small cystic lesions; these can be best viewed by MRI (Farres 2003). At present there is limited evidence to suggest that MRI should be used as a screening or diagnostic test (Decina 2010).

\section{Renal biopsy}

If renal biopsy were to reveal the characteristic renal pathology, it would also be a pointer towards the diagnosis. However, owing to the invasive nature of the investigation, it is not routinely recommended.

\section{What should be done if a patient develops renal insufficiency?}

The patient's physical health should be assessed and the presence of other factors that might explain the decline in renal function should be ascertained. These include associated medical problems (diabetes, hypertension etc.) and other nephrotoxic drugs. Chronic kidney disease is a risk factor for cardiovascular disease; other risk factors for both diseases, such as obesity, family history, smoking and alcohol misuse, also need to be assessed. In collaboration with the general practitioner (GP), one should try to optimise the treatment of comorbid physical illnesses and avoid other potentially nephrotoxic medication.

Chronic kidney disease is a common and treatable illness. Its incidence increases with age, so renal insufficiency is particularly common in elderly patients on lithium. The aim of treatment is to reduce the progression of chronic kidney disease and the risk of cardiovascular disease. The standard interventions for chronic kidney disease, such as angiotensin-converting enzyme (ACE) inhibitors, diuretics and sodium-restricted diets, can also potentially increase serum lithium levels, so levels should be closely monitored. Despite very limited evidence about the relationship between dosage of lithium and renal function, decreasing the dosage to the minimum that is effective may reduce the risk of further deterioration; it will also reduce the risk of lithium intoxication (Kehoe 1994; Presne 2003).

In the absence of any active renal disease, lithium can be safely continued until the eGFR falls below $60 \mathrm{ml} / \mathrm{min} / 1.73 \mathrm{~m}^{2}$ (Kripalani 2009). If the eGFR dips below this level, with or without any other evidence of renal disease, renal function should be closely monitored as shown in Table 3 . This should also prompt further consideration of a risk-benefit analysis of ongoing lithium therapy (Box 2). 


\begin{tabular}{|c|c|c|c|}
\hline $\begin{array}{l}\text { Stage of chronic } \\
\text { kidney disease }^{\text {a }}\end{array}$ & $\begin{array}{c}\text { eGFR }\left(\mathrm{ml} / \mathrm{min} / 1.73 \mathrm{~m}^{2}\right. \\
\text { body surface) }\end{array}$ & Proteinuria & Action \\
\hline $\begin{array}{l}\text { Normal kidney function } \\
\text { or stage } 1 \text { or } 2\end{array}$ & $>60$ & $\begin{array}{l}\text { Urine analysis: test urine for } \\
\text { albumin:creatinine ratio } 3 \text { months after } \\
\text { starting lithium; if no previous ratio is } \\
\text { available, check initially - if normal, no } \\
\text { regular monitoring is required }\end{array}$ & $\begin{array}{l}\text { Measure estimated glomerular filtration rate annually; } \\
\text { monitor blood pressure annually; }{ }^{b} \text { if heavy proteinuriac }{ }^{c} \text { is } \\
\text { present, refer to nephrology; if proteinuria (not heavy) }{ }^{d} \text { is } \\
\text { present, monitor albumin:creatinine ratio annually }\end{array}$ \\
\hline $\begin{array}{l}\text { Moderately reduced } \\
\text { eGFR (stages } 3 a, 3 b)\end{array}$ & $\begin{array}{l}45-59 \text { (stage 3a), } \\
30-44 \text { (stage } 3 b)\end{array}$ & $\begin{array}{l}\text { Test urine for albumin:creatinine ratio; } \\
\text { confirm abnormal result with early- } \\
\text { morning sample; do reagent strip test for } \\
\text { haematuria if proteinuria is confirmed }\end{array}$ & 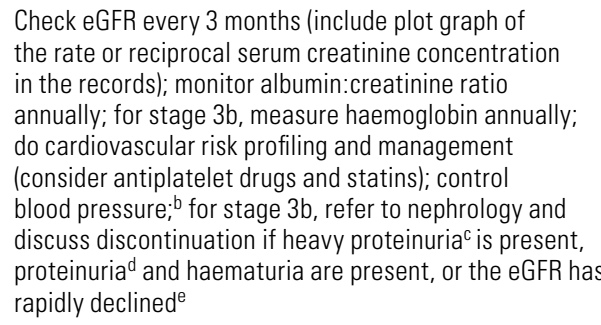 \\
\hline $\begin{array}{l}\text { Severely reduced eGFR } \\
\text { (stages } 4 \text { and 5) }\end{array}$ & $\begin{array}{c}15-29 \text { (stage } 4) \\
<15(\text { stage } 5)\end{array}$ & As for stages $3 a$ and $3 b$ & Refer to nephrology; lithium is normally contraindicated \\
\hline
\end{tabular}

eGFR, estimated glomerular filtration rate.

See NICE guidelines CG73 and CG66 (National Collaborating Centre for Chronic Conditions 2008a,b) for additional advice on use of angiotensin converting enzyme inhibitors for chronic kidney disease in diabetes.

a. Staging is according to NICE guideline CG73 (National Collaborating Centre for Chronic Conditions 2008a).

b. Blood pressure controlled to $<140 \mathrm{mmHg}$ systolic and $90 \mathrm{mmHg}$ diastolic (lower in diabetes or heavy proteinuria).

c. Heavy proteinuria corresponds to an albumin:creatinine ratio of $0.70 \mathrm{mg} / \mathrm{mmol}$.

d. Proteinuria corresponds to an albumin:creatinine ratio of $0.30 \mathrm{mg} / \mathrm{mmol}$

e. A decline of $>5 \mathrm{ml} / \mathrm{min}$ over 1 year or $>10 \mathrm{ml} / \mathrm{min}$ over 5 years.

\section{What factors should be considered when making the risk-benefit analysis?}

It is not unusual to find gradually declining eGFR or progressively increasing creatinine levels in patients on long-term lithium treatment. The decision to either continue or discontinue lithium in such situations is a fine trade-off between the

BOX 2 Risks and benefits of continuing or discontinuing lithium in patients with renal insufficiency

\section{Continuing lithium}

Risks

\section{Discontinuing lithium}

Progressive decline of renal functions, leading to stage 5 chronic kidney disease

Chronic kidney disease is a risk factor for cardiovascular disease, and most patients with chronic kidney disease are likely to die from cardiovascular disease rather than from stage 5 chronic kidney disease Increased risk of lithium toxicity

Benefits

\section{Stable mental health}

Reduced risk of suicide

Possible prevention, or role in prevention, of Alzheimer's dementia (Young 2011)
Risks

Risk of relapse of mental illness increases about 17-fold in major affective disorders

Patients with bipolar disorder are three times more likely to relapse than those with other major affective disorders

Increased risk of suicidal acts and suicide Little is known about whether the risk of suicide/self-harm would decrease if patients were switched to other mood stabilisers

\section{Benefits}

Possible improvement of renal function or reduction in rate of decline of renal function, especially if lithium is stopped at an earlier stage of chronic kidney disease benefit of stable mental health and reduced risk of suicide $v$. the (difficult to predict) risk of further deterioration of renal function and cardiovascular disease, leading to increased physical morbidity and mortality. Usually, the benefit of continuing lithium can be assessed on the basis of the patient's diagnosis and response to the drug. However, the assessment of risk is difficult, as there is no definitive evidence base for predicting the magnitude of risk of cardiovascular disease or CKD 5. In bipolar disorder, discontinuing lithium leads to a markedly increased relapse rate and suicide risk (Baldessarini 1999). Furthermore, relapses may be more severe and treatmentrefractory than previous episodes (Ferrier 2006). Responses to alternative agents (anticonvulsants and/or atypical antipsychotics) cannot be predicted accurately, and these agents also come with their own 'baggage' of adverse effects, such as metabolic syndrome.

In cases of chronic kidney disease, discontinuation of lithium should be considered, as this is expected to reverse the loss of renal function or at least halt or slow down its decline. Again, predicting the risks of further deterioration of renal function is also very difficult. First, in the presence of multiple risk factors for chronic kidney disease it will be a futile, and to some extent impossible, task to attribute renal impairment to lithium. Moreover, renal function may not improve 
or decline further even after discontinuation of lithium (Werneke 2012). Nevertheless, only a small proportion of patients in the initial stages of chronic kidney disease progress to stage 5 . Last, patients with chronic kidney disease are more likely to die as a result of cardiovascular disease than renal failure (National Collaborating Centre for Chronic Conditions 2008a). Hence, it is difficult to discuss the risks and benefits with precision. Doctors need to make a clinical judgement, taking into consideration the patient's preference.

\section{When should patients be referred to nephrology services?}

Severe and complex cases should be referred to nephrologists (Box 3), but the referral is for the management of chronic kidney disease and its complications, not for making the decision about continuation or discontinuation of lithium. The referral letter should be accompanied by a detailed risk assessment from a mental health perspective, including risk of relapse and suicide (Werneke 2012).

\section{When should lithium be stopped?}

The decision when to stop lithium is a complex one. Glomerular function can improve if lithium is stopped at an early stage, but after a certain point renal function continues to decline even after discontinuation of the drug. Markowitz et al (2000) studied 24 cases of biopsy-proven lithium toxicity. Follow-up data were available for 19 of the patients in this cohort. Lithium was discontinued either before or immediately after the biopsy. Despite discontinuation of lithium, 7 of the 9 patients with initial serum creatinine values $>2.5 \mathrm{mg} / \mathrm{dl}(221 \mu \mathrm{mol} / \mathrm{l})$ progressed to end-stage renal disease, as opposed to 1 of the 10 patients

BOX 3 When to refer to nephrology services

- If the patient has stage 4 or 5 chronic kidney disease

- If there is heavy proteinuria $(A C R \geq 70 \mathrm{mg} / \mathrm{mmol}$, roughly equivalent to $P C R \geq 100 \mathrm{mg} / \mathrm{mmol}$, or urinary protein excretion $\geq 1 \mathrm{~g} / 24 \mathrm{~h}$ ), unless known to be due to diabetes and already appropriately treated

- If there is proteinuria (ACR $\geq 30 \mathrm{mg} / \mathrm{mmol}$, roughly equivalent to $P C R \geq 50 \mathrm{mg} / \mathrm{mmol}$, or urinary protein excretion $\geq 0.5 \mathrm{~g} / 24 \mathrm{~h}$ ) together with haematuria

- If there is rapidly declining eGFR (>5 ml/min $/ 1.73 \mathrm{~m}^{2}$ over 1 year, or $>10 \mathrm{ml} / \mathrm{min} / 1.73 \mathrm{~m}^{2}$ over 5 years)

ACR, albumin:creatinine ratio; PCR, protein:creatinine ratio; eGFR, estimated glomerular filtration rate

(National Collaborating Centre for Chronic Conditions 2008a with serum creatinine $<2.5 \mathrm{mg} / \mathrm{dl}$. One patient in the cohort died by suicide after coming off lithium. Presne et al (2003) reported that patients with proteinuria were more likely to progress to end-stage renal disease than those without. Within their cohort, renal function continued to deteriorate in all patients whose lithium was discontinued when baseline creatinine clearance was less than $25 \mathrm{ml} / \mathrm{min}$. In contrast, if lithium was discontinued when creatinine clearance was above $40 \mathrm{ml} / \mathrm{min}$, renal function improved in five out of seven patients. Hence, although there is no established determining threshold for creatinine clearance, it may lie between 25 and $40 \mathrm{ml} /$ min. There is lack of evidence to suggest how long one should wait to see the effect of lithium discontinuation, as it can vary from a few months to several years.

Lithium should normally be stopped in patients with stage 4 or 5 chronic kidney disease, because of the increased risk of lithium toxicity (Kripalani 2009). However, if their mental health deteriorates with alterative psychiatric treatments, lithium can be restarted even in patients undergoing haemodialysis, although this requires the serum lithium level to be assiduously maintained within the therapeutic range, and close liaison with a nephrologist (Knebel 2010).

Since CKD 5 is not a common outcome even for people at CKD stages 1-3, in most cases risk-benefit analysis would favour continuation of lithium (Gitlin 1999). Gitlin's position has more recently been supported by Werneke et al (2012), who applied a mathematical model based on the existing evidence to analyse the risks and benefits of continuing or discontinuing lithium in people with chronic kidney disease. They suggest that lithium should be continued in the majority of patients even if they develop long-term renal adverse effects, unless the likelihood of progression to end-stage renal disease exceeds $41.3 \%$ or anticonvulsant medication is found to outperform lithium in relapse prevention.

Owing to uncertainties about risks and benefits, the decision to continue or discontinue lithium will never be easy. Ideally, it should be jointly made by the patient, GP, psychiatrist and nephrologist.

\section{Hypercalcaemia and hyperparathyroidism}

A recent systematic review and meta-analysis (McKnight 2012) found that blood calcium and parathyroid hormone levels were up to $10 \%$ higher in patients on lithium compared with controls (healthy individuals and psychiatric patients). Another review reported that hypercalcaemia 
with either increased or normal parathyroid levels develops in between 15 and $60 \%$ of patients on lithium (Khandwala 2006). The prevalence of hypercalcaemia is higher in patients with renal failure (owing to hypocalciuria), and nephrolithiasis and nephrocalcinosis are known complications (Grunfeld 2009). These are usually long-term side-effects, although overt hyperparathyroidism has been reported as early as 1-2 months after the initiation of lithium (Szalat 2009).

It is proposed that lithium affects the parathyroid glands by its action on calcium-sensitive receptors. These receptors, when activated by higher calcium levels, inhibit the release of parathyroid hormone. Lithium raises the set point of calciumtriggered parathyroid secretion by antagonising these receptors (Gregoor 2007). Lithium also inhibits the renal secretion of calcium, and most probably directly acts on the parathyroid gland as well. Lithium-associated hyperparathyroidism frequently presents with either single or multiple adenomas; occasionally, it is also associated with diffuse hyperplasia (Saunders 2009).

Hypercalcaemia is usually first picked up by routine annual blood screening, especially if it is mild and asymptomatic. However, patients can present with a variety of psychological and somatic symptoms, depending on the severity of hypercalcaemia. Psychiatric manifestations include depression, anxiety, obsessive-compulsive symptoms and cognitive impairment. Common physical symptoms are dyspepsia, nephrolithiasis, nephrocalcinosis, renal impairment and osteoporosis (Presne 2003; Broome 2011).

a. Nephrotic syndrome in which light microscopy reveals either normal glomeruli or very minimal histopathological changes.

\section{Management of hypercalcaemia and hyperparathyroidism}

The management of lithium-associated hypercalcaemia and hyperparathyroidism depends on the severity and associated complications. If a patient is asymptomatic (and without any associated complications), then lithium can be continued with close monitoring of calcium and parathyroid hormone levels. However, if a patient has moderate to severe hypercalcaemia and/ or presents with symptoms of hypercalcaemia or suffers from its complications, a referral should be made to an endocrinologist for further investigations and treatment.

If lithium-associated hypercalcaemia or hyperparathyroidism is suspected, after excluding other common aetiological factors, gradually withdrawing lithium and starting the patient on another appropriate psychotropic drug should be considered, after careful risk-benefit analysis. There are contradictory reports about the normalisation of hypercalcaemia after lithium withdrawal (Szalat 2009). If hypercalcaemia continues even after withdrawal of lithium, or if the risk-benefit analysis results in the decision to continue lithium, hypercalcaemia/ hyperparathyroidism can be managed by medical or surgical means.

The calcimimetic drug cinacalcet is an allosteric activator of calcium-sensing receptors throughout the body, functioning in a manner exactly opposite to lithium, lowering the set point of calciumtriggered parathyroid secretion. Over the past 6 years, a few small case series have reported the successful treatment of lithium-associated hyperparathyroidism using cinacalcet (Gregoor 2007).

Like primary hyperparathyroidism, lithiumassociated hyperparathyroidism is treated surgically. The surgical interventions range from unilateral/focused parathyroidectomy to subtotal parathyroidectomy. Most case reports have suggested favourable outcomes after the surgical intervention (Saunders 2009). However, recurrences have also been reported after focused parathyroidectomy (Broome 2011).

\section{Nephrotic syndrome}

Lithium can also cause nephrotic syndrome. This was first reported by Duflot et al in 1973. Since then, about 26 cases of nephrotic syndrome have been reported. Usually, it appears within the first year of initiation of lithium, but it has been reported up to 20 years later (Bosquet 1997).

The pathophysiological basis is not clear. Renal biopsies, when done, usually show features suggestive of minimal change disease ${ }^{\text {a }}$ (Bosquet 1997). Patients present with marked oedema, proteinuria, hypoalbuminemia, and often hyperlipidemia. It is commonly complicated by venous thromboembolism (due to loss of clotting factors), infections (due to loss of immunoglobulins) and renal failure. Most patients improve after discontinuation of lithium, but the syndrome may recur on rechallenge (Gitlin 1999).

\section{Management}

If nephrotic syndrome is suspected, lithium should be stopped as soon as possible and the patient should be referred to a nephrologist for further management. Lithium needs to be stopped because of the increased risk of acute renal failure, lithium toxicity and potential interactions with diuretics and ACE inhibitors. If, after a careful risk-benefit analysis, it is subsequently decided to reintroduce lithium (depending on the past response to lithium and other medications, severity of the psychiatric illness, and the possibility of association between 
lithium and nephrotic syndrome), patients should be carefully monitored for the risk of recurrence.

\section{Acute renal failure}

Lithium intoxication can cause acute renal failure. This might result from volume depletion secondary to lithium intoxication or vice versa (Lederer 2012). Very rarely, lithium intoxication can also cause neuroleptic malignant syndrome, which can also lead to acute renal failure (Gill 2003). It usually responds well to management of fluid and electrolyte imbalances and dialysis, but long-term neurological and renal adverse effects can occur.

\section{Distal tubular acidosis}

Longer-term use of lithium may cause a mild incomplete distal tubular acidosis in patients with and without reduced urine osmolarity. This effect is unlikely to be clinically relevant (Gitlin 1999).

\section{Conclusions}

Over recent decades, accruing evidence about the benefits of lithium has led to resurgence of interest in its clinical use. Although knowledge about its renal adverse effects is still far from satisfactory, the limited evidence does give a basis for monitoring and management of a range of renal pathology, as outlined here. Hopefully, further research in this area will help us to quantify these risks and identify their determinants. Fully evidence-based monitoring and management of renal adverse effects would minimise the side-effect burden and optimise the use of lithium.

\section{References}

Baldessarini RJ, Tondo L, Viguera AC (1999) Discontinuing lithium maintenance treatment in bipolar disorders: risks and implications. Bipolar Disorder 1: 17-24.

Bassilios N, Martel P, Godard V, et al (2008) Monitoring of glomerular filtration rate in lithium-treated outpatients: an ambulatory laboratory database surveillance. Nephrology Dialysis Transplantation 23: 562-5.

Bendz H, Aurell M, Balldin J, et al (1994) Kidney damage in long-term lithium patients: a cross-sectional study of patients with 15 years or more on lithium. Nephrology Dialysis Transplantation 9: 1250-4.

Bendz H, Schon S, Attman PO, et al (2010) Renal failure occurs in chronic lithium treatment but is uncommon. Kidney Internationa/ 77: 219-24.

Bosquet S, Descombes E, Gauthier T, et al (1997) Nephrotic syndrome during lithium therapy. Nephrology Dialysis Transplantation 12: 2728-31.

Boton R, Gaviria M, Batlle DC (1987) Prevalence, pathogenesis, and treatment of renal dysfunction associated with chronic lithium therapy. American Journal of Kidney Diseases 10: 329-45.

Broome JT, Solorzano CC (2011) Lithium use and primary hyperparathyroidism. Endocrine Practice 17 (suppl 1): 31-5.

Decina P, Pedicelli C, Diana G, et al (2010) Lithium-induced tardive nephropathy: MRI contribution to the detection of pre-symptomatic renal abnormalities. Journal of Psychopathology 16: 321-5.
DePaulo JR Jr, Correa El, Sapir DG (1986) Renal function and lithium: a longitudinal study. American Journal of Psychiatry 143: 892-5.

Duflot JP, Dore C, Fellion G, et al (1973) Use of lithium carbonate in a psychiatric institution. Annales Medico Psychologiques 2: 311-21.

Farres MT, Ronco P, Saadoun D, et al (2003) Chronic lithium nephropathy: MR imaging for diagnosis. Radiology 229: 570-4.

Ferrier IN, Ferrie LJ, Macritchie KA (2006) Old drug, new data: revisiting... lithium therapy. Advances in Psychiatric Treatment 12: 256-64.

Gill J, Singh H, Nugent K (2003) Acute lithium intoxication and neuroleptic malignant syndrome. Pharmacotherapy 23: 811-5.

*Gitlin M (1999) Lithium and the kidney: an updated review. Drug Safety 20: $231-43$.

*Grandjean EM, Aubry JM (2009) Lithium: updated human knowledge using an evidence-based approach. Part III: clinical safety. CNS Drugs 23: $397-418$

Gregoor PS, de Jong GM (2007) Lithium hypercalcaemia, hyperparathyroidism, and cinacalcet. Kidney International 71: 470.

${ }^{*}$ Grunfeld JP, Rossier BC (2009) Lithium nephrotoxicity revisited. Nature Reviews Nephrology 5: 270-6.

Ishani A, Grandits GA, Grimm RH, et al (2006) Association of single measurements of dipstick proteinuria, estimated glomerular filtration rate and hematocrit with the 25 year incidence of end-stage renal disease in the Multiple Risk Factor Intervention Trial. Journal of the American Society of Nephrology 17: 1444-52.

* Jefferson JW (2010) A clinician's guide to monitoring kidney function in lithium-treated patients. Journal of Clinical Psychiatry 71: 1153-7.

Kanfer A, Blondiaux I (2000) Renal and metabolic complications of lithium. Nephrologie 21: 65-70.

Kehoe RF (1994) A cross-sectional study of glomerular function in 740 unselected lithium patients. Acta Psychiatrica Scandinavica 89: $68-71$.

Khandwala HM, Van Uum S (2006) Reversible hypercalcaemia and hyperparathyroidism associated with lithium therapy: case report and review of literature. Endocrine Practice 12: 54-8.

Knebel RJ, Rosenlicht N, Collins L (2010) Lithium carbonate maintenance therapy in a hemodialysis patient with end-stage renal disease. American Journal of Psychiatry 167: 1409-10.

*Kripalani M, Shawcross J, Reilly J, et al (2009) Lithium and chronic kidney disease. BMJ 339: b2452.

Kusalic M, Engelsmann F (1996) Renal reactions to changes of lithium dosage. Neuropsychobiology 34: 113-6.

Lederer E, Dacso CC, Tran MD (2012) Lithium nephropathy. Medscape Reference: Drugs, Diseases \& Procedures (http://emedicine.medscape. com/article/242772, accessed 4 July 2012).

*Lepkifker E, Sverdlik A, lancu I, et al (2004) Renal insufficiency in longterm lithium treatment. Journal of Clinical Psychiatry 65: 850-6.

Markowitz GS, Radhakrishnan J, Kambham N, et al (2000) Lithium nephrotoxicity: a progressive combined glomerular and tubulointerstitial nephropathy. Journal of the American Society of Nephrology 11: $1439-48$

McKnight RF, Adida M, Budge K, et al (2012) Lithium toxicity profile: a systematic review and meta-analysis. Lancet 379: 721-8.

Miller AL, Bowden CL, Plewes J (1985) Lithium and impairment of renal concentrating ability. Journal of Affective Disorder 9: 115-9.

National Collaborating Centre for Chronic Conditions (2008a) Chronic Kidney Disease: Early Identification and Management of Chronic Kidney Disease in Adults in Primary and Secondary Care (NICE Clinical Guideline 73). National Institute for Health and Clinical Excellence.

National Collaborating Centre for Chronic Conditions (2008b) Type 2 Diabetes: The Management of Type 2 Diabetes (NICE Clinical Guideline 66). National Institute for Health and Clinical Excellence.
MCO answers

$1 \mathrm{a} \quad 2 \mathrm{~b} \quad 3 \mathrm{~d} \quad 4 d \quad 5 \mathrm{~b}$ 
National Collaborating Centre for Mental Health (2006) Bipolar Disorder: The Management of Bipolar Disorder in Adults, Children and Adolescents in Primary and Secondary Care (NICE Clinical Guideline 38). National Institute for Health and Clinical Excellence.

*Presne C, Fakhouri F, Noël LH, et al (2003) Lithium-induced nephropathy: rate of progression and prognostic factors. Kidney International 64: 585-92.

*Raja M (2011) Lithium and kidney, 60 years later. Current Drug Safety 6: 291-303.

Reilly JG, Close H, Main J, et al (2009) Renal outcomes in people with bipolar disorder treated with lithium: a retrospective cohort database study. Pharmacoepidemiology and Drug Safety 18 (suppl 1): S202.

Saunders BD, Saunders EF, Gauger PG (2009) Lithium therapy and hyperparathyroidism: an evidence-based assessment. World Journal of Surgery 33: 2314-23.

Schou M (2003) Lithium prophylaxis: myths and realities. Focus 1: 53-7.

Stevens LA, Coresh J, Greene T, et al (2006) Assessing kidney function: measured and estimated glomerular filtration rate. New England Journal of Medicine 354: 2473-83.
Stevens LA, Coresh J, Feldman HI, et al (2007) Evaluation of the modification of diet in renal disease study equation in large diverse population. Journal of the American Society of Nephrology 18: 2749-57.

Stone KA (1999) Lithium-induced nephrogenic diabetes insipidus. Journal of the American Board of Family Medicine 12: 43-7.

Szalat A, Mazeh H, Freund HR (2009) Lithium-associated hyperparathyroidism: report of four cases and review of the literature. European Journal of Endocrinology 160: 317-23.

Weinstein JR, Anderson S (2010) The aging kidney: physiological changes. Advances in Chronic Kidney Disease 17: 302-7.

Werneke U, Ott M, Renberg ES, et al (2012) A decision analysis of longterm lithium treatment and the risk of renal failure. Acta Psychiatrica Scandinavica 126: 186-97.

Young $\mathrm{AH}$, Hammond JM (2007) Lithium in mood disorders: increasing evidence base, declining use? British Journal of Psychiatry 191: 474-6.

Young $\mathrm{AH}$ (2011) More good news about the magic ion: lithium may prevent dementia. British Journal of Psychiatry 198: 336-7.

${ }^{*}$ An asterisk denotes recommended further reading.

\section{MCOs}

Select the single best option for each question stem

1 The most common renal adverse effect of lithium is:

a impaired urinary concentration

b renal insufficiency

c renal failure

d nephrotic syndrome

e hyperparathyroidism.

2 Lithium-associated renal failure is:

a a common adverse effect

b an uncommon to rare adverse effect

c a very rare adverse effect

$\mathrm{d}$ a misnomer as lithium does not cause renal failure

e a consequence of physical morbidity unrelated to the drug itself.
3 The most useful investigation in monitoring renal function in patients on lithium is:

a serum creatinine

b serum urea

c creatinine clearance

d eGFR

e urinary albumin:creatinine ratio.

4 If a blood test of a patient on lithium shows an eGFR of $54 \mathrm{ml} / \mathrm{min}$ then the first step should be:

a ignore it as it is of no clinical significance

b urgently refer the patient to a nephrologist

c stop lithium immediately and switch to another drug

d review the patient's previous blood results, along with medical and psychiatric history e admit the patient to a medical ward.
5 According to the NICE guideline on bipolar disorder, renal function should be monitored:

a every 3 months

b every 6 months

c every 2 months

d once a year

e once a month. 